1 Fundação Oswaldo Cruz (Fiocruz), Instituto Nacional de Controle de Qualidade em Saúde (INCQS) - Rio de Janeiro (RJ), Brasil. Instituto Nacional de Câncer José Alencar Gomes da Silva (Inca), Coordenação de Prevenção e Vigilância, Unidade Técnica de Exposição Ocupacional, Ambiental e Câncer - Rio de Janeiro (RJ), Brasil. vicosta@inca.gov.br

2 Instituto Nacional de Câncer José Alencar Gomes da Silva (Inca),

Coordenação de Prevenção e Vigilância, Unidade

Técnica de Exposição Ocupacional, Ambiental e Câncer - Rio de Janeiro (RJ), Brasil. Universidade Federal do Estado do Rio de Janeiro (Unirio) - Rio de Janeiro (RJ), Brasil. mmello@inca.gov.br

3 Fundação Oswaldo Cruz (Fiocruz) - Rio de Janeiro (RJ), Brasil. Universidade Federal do Estado do Rio de Janeiro (Unirio) - Rio de Janeiro (RJ), Brasil.

karenfriedrich@hotmail.com

\section{Exposição ambiental e ocupacional a agrotóxicos e o linfoma não Hodgkin}

\section{Environmental and occupational exposure to pesticides and the non- Hodgkin lymphoma}

RESUMO Este ensaio versa sobre a exposição a agrotóxicos e o risco de desenvolvimento de linfoma não Hodgkin (LNH), um tipo de câncer hematológico que teve aumento progressivo nas últimas décadas no Brasil e no mundo. Foi realizada uma revisão integrativa para avaliar a associação de agrotóxicos com a indução de LNH. A pesquisa mostrou que os agrotóxicos ácido diclorofenoxiacético (2,4-D), diazinona, glifosato e malationa estão associados a essa neoplasia e compartilham alguns mecanismos de carcinogenicidade. Essas informações podem subsidiar medidas regulatórias mais restritivas e que contemplem a realidade da exposição a misturas de agrotóxicos, amplamente utilizados no meio rural e urbano.

PALAVRAS-CHAVE Exposição ocupacional. Saúde do trabalhador. Agroquímicos. Linfoma não Hodgkin. \begin{abstract}
This essay deals with the exposure to pesticides and the risk of non-Hodgkin lymphoma (NHL) development, a type of hematological cancer that has progressively increased in recent decades in Brazil and the world. An integrative review was conducted to evaluate the association of pesticides with the induction of $N H L$. The research showed that the pesticides dichlorophenoxyacetic acid (2,4-D), diazinon, glyphosate and malathion are associated with this neoplasia and share some mechanisms of carcinogenicity. This information may subsidize more restrictive regulatory measures and that contemplate the reality of the exposure to mixtures of pesticides, widely used in rural and urban environments.
\end{abstract}

KEYWORDS Occupational exposure. Occupational health. Agrochemicals. Non-Hodgkin lymphoma. 


\section{Introdução}

O uso intensivo de agrotóxicos na agricultura brasileira teve seu marco inicial no período denominado Revolução Verde, caracterizado pela ampla disseminação e o aumento de novas práticas agrícolas após a Segunda Guerra Mundial, que incluía o uso de agrotóxicos (CARNeIRO ET AL., 2015). Desde a década de 1960, em especial, após a publicação do livro 'Primavera silenciosa', a população mundial vem se preocupando com os impactos do uso indiscriminado desses agentes químicos.

Ao longo dos anos, os padrões de uso dos Ingredientes Ativos (IAs) de agrotóxicos modificaram-se, em especial, nos países em desenvolvimento, devido ao modelo de produção agrícola mais voltado para a produção de commodities e à fragilidade das estruturas legislativa e regulatória (CARNEIRO ET AL., 2015).

O modelo de agricultura hegemônico no Brasil, que tem como base de sustentação o cultivo de grandes extensões de terra, a pulverização de agrotóxicos e a utilização de sementes transgênicas, principalmente, as resistentes a herbicidas, é um modelo insustentável sob vários aspectos, entre os quais: a) grandes extensões de terra onde se cultiva uma única espécie de vegetal (por exemplo, soja, milho ou algodão) criam o ambiente propício para a proliferação das espécies que têm preferência por essas culturas; b) o uso intenso de agrotóxicos leva ao desenvolvimento de resistência dos vetores e plantas indesejáveis; e c) a liberação comercial de sementes transgênicas resistentes a herbicidas, como o glifosato e o 2,4-D, é determinante para o uso dessa classe de agrotóxicos. Deve-se destacar que os herbicidas estão entre os grupos de agrotóxicos mais utilizados no Brasil, como a atrazina, o paraquat, o glifosato e o 2,4-D, que, em 2012, somaram mais de 200 mil toneladas comercializadas. Consequentemente, esses fatores resultam tanto no incremento do volume de uso de agrotóxicos por hectare como no uso de misturas de ingredientes ativos que aumentam o risco de impactos negativos para o ambiente e para a saúde humana, levando, por exemplo, à perda da biodiversidade e ao desenvolvimento de doenças, como infertilidade, distúrbios hormonais e câncer (CARNEIRO ET AL., 2015).

Alguns ingredientes ativos de agrotóxicos apresentam associação positiva com a indução de tumores e, por isso, foram classificados recentemente, pela Agência Internacional de Pesquisa em Câncer (International Agency for Research on Cancer - Iarc), dentro dos grupos 2A (provavelmente, carcinogênico para seres humanos) e 2B (possivelmente, carcinogênico para seres humanos), entre eles, destacam-se os herbicidas 2,4-D e glifosato e os inseticidas diazinona e a malationa (IARC, 2015A, 2015B). Embora outros agrotóxicos ainda não tenham sido classificados quanto à carcinogenicidade na Iarc, eles demonstram resultados positivos em estudos epidemiológicos e também têm sido um dos principais alvos de investigação na etiologia de diferentes tipos de câncer, como o LNH (SCHINASl; LEON, 2014).

\section{Câncer e linfoma não Hodgkin no mundo e no Brasil: epidemiologia e etiologia}

O câncer é composto por mais de 100 doenças, que possuem como característica o crescimento desordenado das células, invasão de tecidos adjacentes e perda das funções essenciais. Entre os cânceres hematológicos, o LNH é o mais incidente, sendo que as maiores taxas de incidência dessa neoplasia são observadas nos países industrializados, como América do Norte, Austrália, Nova Zelândia e em algumas partes da Europa. $\mathrm{Na}$ atualidade, estima-se que a cada ano ocorram cerca de 390 mil casos novos $(2,7 \%$ do total de câncer) e 200 mil óbitos ( $2,4 \%$ do total de óbitos) por LNH no mundo, com aumento de 
4\% ao ano, aproximadamente. Esse tipo de câncer é observado desde a década de 1970, havendo estabilidade nas taxas de incidência em alguns países desenvolvidos a partir de 1990 (INCA, 2015).

$\mathrm{O}$ aumento da incidência de LNH ao longo das últimas décadas pode ser explicado, pelo menos parcialmente, por melhorias nas técnicas de diagnóstico, na classificação histopatológica e na captação dos casos pelos registros de câncer de base populacional. No caso dos estudos etiológicos, o foco tem sido a exposição a carcinógenos químicos presentes no ambiente de trabalho, no meio ambiente e nos alimentos, sendo um dos principais alvos de estudo da doença (SCHINASI; LEON, 2014).

Estimou-se para o biênio 2016-2017 a ocorrência de, aproximadamente, 410 mil novos casos de câncer em âmbito nacional (excluindo-se os casos de pele não melanoma) (INCA, 2015). Estima-se que as taxas de incidência variem entre 4,1 e 5,4 casos por 100 mil habitantes, sendo 5.210 casos novos de LNH para homens e 5.030 para mulheres. Com relação às regiões brasileiras, Sul e Sudeste apresentam as maiores taxas de incidência para o LNH, para ambos os sexos (figura 1).

Figura 1. Representação das taxas brutas de incidência de linfoma não Hodgkin por 100 mil habitantes, para cada sexo, estimada para o ano de 2016 , por Unidade de Federação
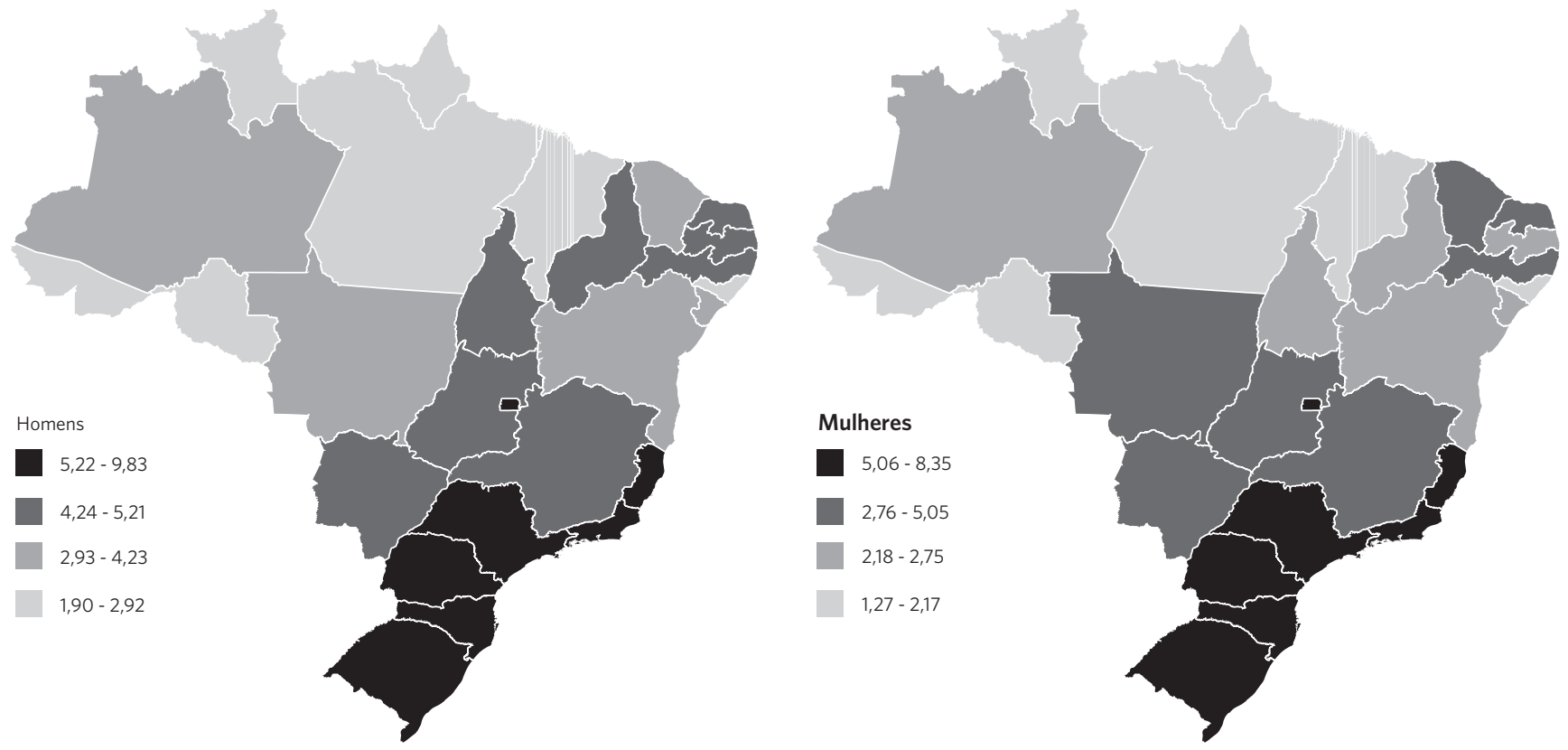

Fonte: Adaptado de Inca (2015).

O LNH é composto por 40 subtipos histológicos oriundos do sistema linfático, e seus mecanismos de formação incluem alterações nos processos de imunorregulação, particularmente, dos linfócitos $\mathrm{T}$, resultando em diminuição das citocinas responsáveis pela resposta imune e pelo aumento do crescimento das células B no tecido linfoide (GREER; REDDY; WILLIANS, 2009). Nem todas as causas da maioria dos casos de LNH estão completamente elucidadas, mas infecção pelo HIV e outros agentes infecciosos, doenças 
autoimunes, imunossupressão, exposição a agentes químicos e algumas ocupações têm sido associadas a essa neoplasia (GREER; REDDY; WILLIANS, 2009; LUO ET AL., 2016).

\section{Linfoma não Hodgkin e exposição a agrotóxicos}

Alguns estudos caso-controle, de coortes e meta-análises, publicados nos últimos dez anos, exploraram a associação entre a exposição a ingredientes ativos de agrotóxicos específicos e o desenvolvimento de LNH (SCHINASI; LEON, 2014). Estudos realizados no Brasil têm apontado correlação entre a incidência e mortalidade do LNH com o consumo per capita de agrotóxicos (sem especificações de ingredientes ativos), como o estudo de Boccolini, Boccolini e Meyer (2015). Desse modo, conhecer os principais ingredientes ativos descritos na literatura associados ao desenvolvimento de LNH pode contribuir para futuras pesquisas e para subsidiar a regulação e as medidas de prevenção e controle do linfoma não Hodgkin.

\section{Metodologia}

Foi realizada uma revisão integrativa em seis etapas, baseada na metodologia de Whitemore e Knafl (2005):

1. Seleção do tema: tendo em vista a falta de dados atuais sistematizados abordando aspectos regulatórios e estudos de carcinogenicidade dos principais ingredientes ativos de agrotóxicos associados ao $\mathrm{LNH}$, esta revisão integrativa permitirá sumarizar dados relevantes, a fim de promover um maior conhecimento do tema em questão.

2. Definição das bases de dados e os descritores: o levantamento bibliográfico usado para este ensaio foi realizado nas bases de dados da Biblioteca Virtual de Saúde (BVS),
Pubmed, Scopus, de artigos publicados no período de 2011 a julho de 2016, através do sistema de busca, com a combinação dos descritores de agrotóxicos e do linfoma não Hodgkin ('Agrochemicals', 'Pesticides', 'desinfesting agent' e 'Lymphoma non-Hodgkin'). A revisão realizada foi abrangente e não incluiu termos relacionados à classificação dos agrotóxicos quanto à sua aplicação (ex.: herbicidas, inseticidas, fungicidas).

3. Estabelecimento dos critérios de seleção dos estudos: a) escritos e publicados nos idiomas português, espanhol, inglês; b) com delineamento do estudo observacional analítico (caso-controle, coorte); c) revisões e meta-análises de estudos observacionais analíticos (caso-controle, coorte); d) com método de obtenção dos dados de exposição através de entrevistas, questionários, matrizes de exposição, marcadores biológicos; e) com dados dos ingredientes ativos (isolados ou misturas) dos agrotóxicos, grupo químico, classes (inseticida, herbicida, fungicida etc.), associados ao LNH. Foram excluídos os trabalhos com as seguintes características: a) escrito em um idioma diferente de português, espanhol, inglês; b) estudos observacionais descritivos (ecológico, transversal); c) sem descrição dos ingredientes ativos, grupo químico e classes de agrotóxicos associados com LNH (e.g. por culturas agrícolas ou pecuária); e) dados de exposição materna e paterna; f) dados oriundos de acidentes; g) informações por subgrupos (e.g. asmáticos); h) comentário, carta ao editor.

4. Leitura dos estudos e identificação dos critérios: foram encontrados nas bases de dados 46 artigos, dos quais, 19 foram excluídos após a análise dos títulos e dos resumos. Dos 28 artigos elegíveis, 12 foram excluídos, pois não atendiam aos demais critérios de inclusão, totalizando 16 artigos desta revisão (quadro 1). 
Quadro 1. Descrição dos estudos selecionados na revisão integrativa da exposição ocupacional e ambiental a agrotóxicos e o risco de desenvolvimento de linfoma não Hodgkin (LNH)

\begin{tabular}{|c|c|c|c|c|c|c|}
\hline \multirow{2}{*}{$\begin{array}{l}\text { Autores } \\
\text { principais }\end{array}$} & \multirow{2}{*}{ Ano } & \multirow{2}{*}{ País } & \multirow{2}{*}{$\begin{array}{l}\text { Desenho } \\
\text { (período) }\end{array}$} & \multirow{2}{*}{ População } & \multicolumn{2}{|r|}{ Exposição a agrotóxicos } \\
\hline & & & & & Mensuração & Grupos químicos ou categorias \\
\hline $\begin{array}{l}\text { Alavanja } \\
\text { MCR }^{1}\end{array}$ & 2014 & EUA & $\begin{array}{l}\text { Coorte prospecti- } \\
\text { va }(1993-1997)\end{array}$ & $\begin{array}{l}54.306 \text { Agriculto- } \\
\text { res e aplicadores }\end{array}$ & $\begin{array}{l}\text { Questionários autoa- } \\
\text { dministrados }\end{array}$ & $\begin{array}{l}\text { Carbamato, dicarboximida ditiocarbamato, dimetil } \\
\text { fosfato, halogenado orgânico, isoftalonitrila, orga- } \\
\text { noclorado, organofosforado, piretroide, xililalanina }\end{array}$ \\
\hline Bertrand KA & 2010 & EUA & $\begin{array}{l}\text { Caso-controle } \\
\text { aninhado }\end{array}$ & $\begin{array}{l}205 \text { homens com } \\
\text { diagnóstico de LNH; } \\
409 \text { controles }\end{array}$ & $\begin{array}{l}\text { Amostra biológica } \\
\text { (sangue) }\end{array}$ & $\begin{array}{l}\text { Organoclorado ( } p, p^{\prime} \text { diclorodifenoldicloroetileno - } \\
\left.p, p^{\prime}-D D E\right)\end{array}$ \\
\hline Bonner MR ${ }^{1}$ & 2010 & EUA & $\begin{array}{l}\text { Coorte prospecti- } \\
\text { va }(1993-1997)\end{array}$ & $\begin{array}{l}57.310 \text { agriculto- } \\
\text { res e aplicadores; } \\
32.347 \text { cônjuges }\end{array}$ & $\begin{array}{l}\text { Questionários autoa- } \\
\text { dministrados }\end{array}$ & Organofosforado (terbufós) \\
\hline Brãuner EV & 2012 & $\begin{array}{l}\text { Dina- } \\
\text { marca }\end{array}$ & $\begin{array}{l}\text { Caso-controle } \\
\text { aninhado (1993- } \\
\text { 1997) }\end{array}$ & $\begin{array}{l}256 \text { pacientes com } \\
\text { LNH; } 256 \text { controles }\end{array}$ & $\begin{array}{l}\text { Concentrações de } \\
\text { organoclorados em } \\
\text { amostras biológicas } \\
\text { (tecido adiposo) }\end{array}$ & Organoclorados \\
\hline Burns $C^{2}$ & 2011 & EUA & $\begin{array}{l}\text { Coorte retros- } \\
\text { pectiva }\end{array}$ & $\begin{array}{l}1.316 \text { homens, } \\
\text { trabalhadores na } \\
\text { produção de 2,4-D; } \\
50 \text { mulheres }\end{array}$ & $\begin{array}{l}\text { Históricos dos traba- } \\
\text { Ihadores }\end{array}$ & Ácido clorofenóxi (2,4-D) \\
\hline Goodman JE & 2015 & - & Meta-análise & $\begin{array}{l}\text { Agricultores, ho- } \\
\text { mens }\end{array}$ & Sem descrição & Ácido clorofenóxi (2,4-D) \\
\hline Hohenadel K & 2011 & Canadá & $\begin{array}{l}\text { Caso-controle de } \\
\text { base populacional } \\
(1991-1994)\end{array}$ & $\begin{array}{l}513 \text { casos de LNH; } \\
1.506 \text { controles }\end{array}$ & $\begin{array}{l}\text { Questionários autoa- } \\
\text { dministrados }\end{array}$ & $\begin{array}{l}\text { Ácido clorofenóxi, fungicida (sem especificação), } \\
\text { herbicida (sem especificação), inseticida (sem espe- } \\
\text { cificação), organoclorado, organofosforado. Misturas: } \\
\text { organofosforado + ácido clorofenóxi, organofosforado } \\
\text { + carbamato, organofosforado + organoclorado, orga- } \\
\text { nofosforado + glicina substituída }\end{array}$ \\
\hline Lerro $\mathrm{CC}^{1}$ & 2015 & EUA & $\begin{array}{l}\text { Coorte prospecti- } \\
\text { va }(1993-1997)\end{array}$ & $\begin{array}{l}57.310 \text { agriculto- } \\
\text { res e aplicadores; } \\
32.347 \text { cônjuges }\end{array}$ & $\begin{array}{l}\text { Questionários autoa- } \\
\text { dministrados }\end{array}$ & Organofosforados \\
\hline Luo D & 2016 & - & Meta-análise & - & $\begin{array}{l}\text { Amostras biológicas } \\
\text { (sangue e tecidos) }\end{array}$ & Organoclorados \\
\hline Pahwa M & 2012 & Canadá & $\begin{array}{l}\text { Caso-controle de } \\
\text { base populacional } \\
(1991-1994)\end{array}$ & $\begin{array}{l}513 \text { casos de LNH; } \\
1.506 \text { controles }\end{array}$ & $\begin{array}{l}\text { Questionários autoa- } \\
\text { dministrados }\end{array}$ & Ácido clorofenóxi, organoclorado, organofosforado \\
\hline Parrón T & 2014 & $\begin{array}{l}\text { Espa- } \\
\text { nha }\end{array}$ & $\begin{array}{l}\text { Caso-controle de } \\
\text { base populacional } \\
(1998-2005)\end{array}$ & $\begin{array}{l}34.205 \text { casos com } \\
\text { câncer; } 1.832 .969 \\
\text { controles }\end{array}$ & $\begin{array}{l}\text { Monitoramento } \\
\text { ambiental }\end{array}$ & Sem especificação \\
\hline $\begin{array}{l}\text { Ruder AM e } \\
\text { Yiin JH }\end{array}$ & 2011 & EUA & $\begin{array}{l}\text { Coorte prospec- } \\
\text { tiva }\end{array}$ & 2.122 agricultores & $\begin{array}{l}\text { Histórico do traba- } \\
\text { Ihador na empresa }\end{array}$ & Fenol clorado (pentaclorofenol) \\
\hline $\begin{array}{l}\text { Schinasi LH e } \\
\text { Leon ME }\end{array}$ & 2014 & - & $\begin{array}{l}\text { Revisão sistemá- } \\
\text { tica, Meta-análise }\end{array}$ & Agricultores & $\begin{array}{l}\text { Questionários autoa- } \\
\text { dministrados }\end{array}$ & $\begin{array}{l}\text { Ácido clorofenóxis, carbamato, cloroacetanilida, } \\
\text { dicarboximida, ditiocarbamato, glicina substituída, } \\
\text { organoclorado, organofosforado, piretroide triazina, } \\
\text { triazinona, tiocarbamato }\end{array}$ \\
\hline Schinasi LH & 2015 & EUA & Coorte & 76.493 mulheres & $\begin{array}{l}\text { Questionários autoa- } \\
\text { dministrados }\end{array}$ & Inseticidas (sem especificação) \\
\hline Viel J & 2011 & França & Caso-controle & $\begin{array}{l}34 \text { casos de LNH; } \\
34 \text { controles }\end{array}$ & $\begin{array}{l}\text { Amostra biológica } \\
\text { (sangue) }\end{array}$ & Organoclorados \\
\hline $\begin{array}{l}\text { Zakerinia } \mathrm{M} ; \\
\text { Namdari } \mathrm{M} ; \\
\text { Amirghofran S }\end{array}$ & 2012 & Irã & $\begin{array}{l}\text { Caso-controle de } \\
\text { base hospitalar } \\
(2007-2008)\end{array}$ & $\begin{array}{l}200 \text { casos de LNH; } \\
200 \text { controles }\end{array}$ & $\begin{array}{l}\text { Entrevistas e questio- } \\
\text { nários }\end{array}$ & $\begin{array}{l}\text { Fungicidas (sem especificação), herbicidas (sem } \\
\text { especificação) }\end{array}$ \\
\hline
\end{tabular}

1 Dados oriundos de uma coorte americana intitulada 'Agricultural Health Study'.

2 Estudo realizado pela empresa Dow Chemical. 
5. Registro dos dados obtidos a partir dos estudos selecionados.

6. Análise e interpretação dos resultados.

\section{Resultados e discussão}

Entre os 16 estudos selecionados na revisão integrativa, estavam incluídas três revisões sistemáticas/meta-análises, que descreveram e/ ou analisaram dados de artigos publicados no período anterior ao estipulado para a revisão (2011). Também, a maioria dos estudos é do tipo coorte, sendo que três desses correspondem à coorte americana intitulada 'Agricultural Health Study'. Ressalta-se que a Iarc publica nas avaliações de carcinogenicidade dos agrotóxicos dados específicos dessa coorte. Quanto aos agrotóxicos avaliados, ácidos clorofenóxis, carbamatos, organoclorados, organofosforados e glicina substituída (glifosato) foram os mais explorados quanto à associação com LNH. Isso pode ser explicado porque esses agentes são os mais comumente utilizados nos meios rural e urbano. Ademais, Hohenadel et al. (2011) avaliaram a exposição a misturas desses agrotóxicos (organofosforado + ácidos fenóxis; organofosforado + carbamato; organofosforado + glicina substituída) com o aumento da chance de apresentar LNH.

Ao total, 35 ingredientes ativos de agrotóxi$\cos$ (isolados) foram avaliados quanto à associação com o risco de desenvolvimento de LNH (quadro 2) nos estudos selecionados na revisão. Desses, 10 apresentam dados de associação positiva com a indução de LNH e já foram classificados quanto ao potencial carcinogênico pela Iarc; como prováveis carcinogênicos para humanos (grupo 2A): DDT, diazinona, glifosato, malationa; possivelmente carcinogênicos para humanos (grupo 2B): 2,4-D, clordano, heptacloro, hexaclorobenzeno, lindano, mirex e pentaclorofenol. Desse modo, através dessas informações, agências regulatórias devem avaliar a restrição de uso ou banimento do registro desses IAs que compõem as formulações de diversos agrotóxicos e medicamentos veterinários. Além disso, mais de um IA pode estar presente nas formulações comerciais ou ser usado de forma concomitante, ou, ainda, misturado nos tanques de aplicação. Essas misturas podem favorecer o desencadeamento de efeitos sinérgicos que contribuem para a carcinogênese.

Quadro 2. Relação dos ingredientes ativos de agrotóxicos quanto à associação com a chance ou o risco de desenvolvimento de linfoma não Hodgkin (LNH) e as classificações da agência internacional, International Agency for Research on Cancer (larc), correspondentes a carcinogenicidade

\begin{tabular}{|c|c|c|c|}
\hline \multirow{2}{*}{ Agrotóxico ( $n^{\circ}$ CAS) } & \multicolumn{2}{|c|}{ Estudos publicados com associação positiva para LNH } & \multirow{2}{*}{$\operatorname{larc}^{3}$} \\
\hline & $\operatorname{Sim}^{1}$ & Não² & \\
\hline \multicolumn{4}{|l|}{ Ácidos clorofenóxi } \\
\hline $2,4-D(94-75-7)$ & Schinasi e Leon (2014) & $\begin{array}{l}\text { Burns et al. (2011), Goodman et al. (2015); } \\
\text { Pahwa et al. (2012), Schinasi e Leon (2014) }\end{array}$ & $2 B(2015)$ \\
\hline MCPA (94-74-6) & Schinasi e Leon (2014) & Pahwa et al. (2012) & NC \\
\hline MCPP (93-65-2) & Pahwa et al. (2012) & - & NC \\
\hline \multicolumn{4}{|l|}{ Carbamato } \\
\hline Aldicarbe (116-06-3) & - & Alavanja et al. (2014) & $3(1991)$ \\
\hline Carbofurano (1563-66-2) & - & Alavanja et al. (2014) & NC \\
\hline Carbaril (63-25-2) & - & Alavanja et al. (2014) & $3(1987)$ \\
\hline \multicolumn{4}{|l|}{ Organoclorado } \\
\hline Aldrin (309-00-2) & - & Alavanja et al. (2014) & $3(1987)$ \\
\hline Clordano (57-74-9) & Luo et al. (2016) & Alavanja et al. (2014) & 2B (2001) \\
\hline
\end{tabular}




\begin{tabular}{|c|c|c|c|}
\hline \multicolumn{4}{|l|}{ Quadro 2. (cont.) } \\
\hline DDE (72-55-9) & Luo et al. 2016 & Viel et al. (2011); Brauner et al. (2012) & NC \\
\hline DDT (50-29-3) & $\begin{array}{l}\text { Alavanja et al. (2014), Brauner et al. } \\
\text { (2012); Pahwa et al. (2012); }\end{array}$ & - & $2 \mathrm{~A}$ \\
\hline Dieldrina (60-57-1) & - & Alavanja et al. (2014), Brauner et al. (2012), & $3(1987)$ \\
\hline Heptacloro (76-44-8) & - & Alavanja et al. (2014) & 2B (2001) \\
\hline Hexaclorobenzeno (HCB) (118-74-1) & Luo et al. (2016) & Brãuner et al. (2012), Viel et al. (2011) & 2B (2001) \\
\hline$\beta-\mathrm{HCH}(319-85-7)$ & - & Brãuner et al. (2012), Viel et al. (2011) & 2B (1987) \\
\hline Lindano $(\mathrm{HCH})(58-89-9)$ & Alavanja et al. (2014); Luo et al. (2016) & Viel et al. (2011) & 2B (1987) \\
\hline Oxiclordano (26880-48-8) & Brauner et al. (2012), Hardell et al. (2009) & Viel et al. (2011) & NC \\
\hline Toxafeno (8001-35-2) & - & Alavanja et al. (2014) & 2B (2001) \\
\hline \multicolumn{4}{|l|}{ Organofosforado } \\
\hline Clorpirifós (2921-88-2) & & Alavanja et al. (2014) & NC \\
\hline Coumafos (56-72-4) & - & Alavanja et al. (2014) & NC \\
\hline Diazinona (333-41-5) & Alavanja et al. (2014) & & $2 \mathrm{~A}$ \\
\hline Diclorvós (DDVP) (62-73-7) & - & Alavanja et al. (2014) & NC \\
\hline Fonofos (944-22-9) & - & Alavanja et al. (2014) & NC \\
\hline Forato (298-02-2) & - & Alavanja et al. (2014) & NC \\
\hline Malationa (121-75-5) & $\begin{array}{l}\text { Hohenadel et al. (2011); Lerro et al. } \\
\text { (2015); Pahwa et al. (2012); }\end{array}$ & Alavanja et al. (2014) & $2 \mathrm{~A}$ \\
\hline Parationa (56-38-2) & - & Alavanja et al. (2014) & $2 \mathrm{~B}$ \\
\hline Terbufós (13071-79-9) & Alavanja et al. (2014) & - & NC \\
\hline \multicolumn{4}{|l|}{ Piretroide } \\
\hline Permetrina (52645-53-1) & - & Alavanja et al. (2014) & $3(1991)$ \\
\hline \multicolumn{4}{|l|}{ Outros } \\
\hline Benomil (17804-35-2) (benzimidazol) & - & Alavanja et al. (2014) & NC \\
\hline $\begin{array}{l}\text { Captana (133-06-2) } \\
\text { (dicarboximida) }\end{array}$ & - & Alavanja et al. (2014) & $3(1987)$ \\
\hline Clorotalonil (1897-45-6) (isoftalonitrila) & - & Alavanja et al. (2014) & 2B (1999) \\
\hline Mancozebe (8018-01-7) (ditiocarbamato) & - & Alavanja et al. (2014) & NC \\
\hline Metalaxil (57837-19-1) (xililalanina) & - & Alavanja et al. (2014) & NC \\
\hline $\begin{array}{l}\text { Metil bromida (74-83-9) (Halogenado } \\
\text { orgânico) }\end{array}$ & Alavanja et al. (2014) & - & 3 (1999) \\
\hline $\begin{array}{l}\text { Glifosato (1071-83-6) } \\
\text { (glicina substituída) }\end{array}$ & Schinasi e Leon (2014) & Schinasi e Leon (2014) & $2 \mathrm{~A}$ \\
\hline pentaclorofenol (87-86-5) (Fenol clorado) & Ruder e Yiin, (2011) & - & 2B (1999) \\
\hline
\end{tabular}

${ }^{1}$ correspondem aos estudos selecionados na revisão (caso-controle, coorte, meta-análises, revisões sistemáticas) que apresentam associação positiva entre a exposição aos ingredientes ativos de agrotóxicos (isolados) com o LNH. A associação positiva é baseada nas medidas de associação (razão de chances, risco relativo) que apresentam resultados maiores que a unidade, com dados estatisticamente significativos.

${ }^{2}$ correspondem aos estudos selecionados na revisão (caso-controle, coorte, meta-análises, revisões sistemáticas) que não apresentaram associação positiva entre a exposição aos ingredientes ativos de agrotóxicos (isolados) com o LNH. A associação negativa é baseada nas medidas de associação (razão de chances, risco relativo) que apresentam resultados menores que a unidade com dados estatisticamente significativos ou dados de associação não estatisticamente significativos.

${ }^{3}$ classificação da larc e o ano correspondente: grupo 2A (provável carcinogênico para humanos); grupo 2B (possível carcinogênico para humanos); grupo 3 (não carcinogênico para humanos); NC (sem classificação). 
Segundo dados coletados junto a organismos reguladores nacionais (Agência Nacional de Vigilância Sanitária - Anvisa; Ministério da Agricultura Pecuária e Abastecimento - Mapa) e internacionais (US Environmental Protection Agency - US EPA; European Food Safety Authority - EFSA), os herbicidas (2,4-D e glifosato) e os inseticidas (diazinona e malationa) são autorizados nos EUA, na União Europeia e amplamente usados no Brasil, tanto na agricultura quanto como inseticidas em campanhas de saúde pública para o controle de vetores (quadro 3) (ABRASCO, 2016). No entanto, deve-se destacar que a legislação americana, diferentemente da brasileira, não restringe o registro de produtos com potencial carcinogênico. Já a legislação europeia passou a adotar esse critério de restrição do registro de agrotóxicos recentemente (CARNEIRO ET AL., 2015; FRIEDRICH, 2013).

Quadro 3. Dados de regulação junto aos órgãos competentes dos principais ingredientes ativos de agrotóxicos associados ao risco de desenvolvimento de linfoma não Hodgkin

\begin{tabular}{|c|c|c|c|c|c|}
\hline \multirow{2}{*}{$\begin{array}{l}\text { Grupo Químico/ Agrotóxico } \\
\left.\text { ( } n^{\circ} \mathrm{CAS}\right)\end{array}$} & \multicolumn{2}{|r|}{ Usos no Brasil } & \multirow{2}{*}{ Anvisa } & \multirow{2}{*}{ US EPA } & \multirow{2}{*}{ EFSA } \\
\hline & Tipo & Culturas e uso não agrícola & & & \\
\hline \multicolumn{6}{|l|}{ Ácidos clorofenóxi } \\
\hline $2,4-D(94-75-7)$ & Herbicida & $\begin{array}{l}\text { Arroz, aveia, café, cana-de-açúcar, } \\
\text { centeio, cevada, milho, pastagem, soja, } \\
\text { sorgo, trigo. }\end{array}$ & Autorizado & Autorizado & Autorizado \\
\hline \multicolumn{6}{|l|}{ Organoclorado } \\
\hline Clordano (57-74-9) & - & - & Não registrado & Não autorizado & Não autorizado \\
\hline DDT (50-29-3) & - & - & Excluído & Não autorizado & Não autorizado \\
\hline Dieldrina (60-57-1) & - & - & Não registrado & Não autorizado & Não autorizado \\
\hline Heptacloro (76-44-8) & - & - & Excluído & Não autorizado & Não autorizado \\
\hline $\begin{array}{l}\text { Hexaclorobenzeno (HCB) } \\
(118-74-1)\end{array}$ & - & - & Não registrado & Não autorizado & Não autorizado \\
\hline Lindano $(\mathrm{HCH})(58-89-9)$ & - & - & Excluído & Não autorizado & Não autorizado \\
\hline Mirex (2385-85-5) & - & - & Não registrado & Não autorizado & Não autorizado \\
\hline \multicolumn{6}{|l|}{ Organofosforado } \\
\hline Diaziona (333-41-5) & Inseticida e acaricida & $\begin{array}{l}\text { Citros, maçã } \\
\text { Domissanitário: líquidos premidos ou } \\
\text { não, jardinagem amadora. }\end{array}$ & Autorizado & Autorizado & Não autorizado \\
\hline Malationa (121-75-5) & Inseticida e acaricida & $\begin{array}{l}\text { Alface, algodão, arroz, berinjela, bró- } \\
\text { colis, cacau, café, citros, couve, couve- } \\
\text {-flor, feijão, maçã, milho, morango, } \\
\text { orquídeas, pastagens, pepino, pera, } \\
\text { pêssego, repolho, rosa, soja, sorgo, } \\
\text { tomate, trigo. Domissanitário: líquidos } \\
\text { premidos ou não; jardinagem amadora; } \\
\text { campanhas de saúde pública. }\end{array}$ & Autorizado & Autorizado & Autorizado \\
\hline \multicolumn{6}{|l|}{ Outros } \\
\hline $\begin{array}{l}\text { Metil bromida } \\
\text { (Halogenado) }\end{array}$ & - & - & Não registrado & Autorizado & Não autorizado \\
\hline
\end{tabular}


Quadro 3. (cont.)

\begin{tabular}{|c|c|c|c|c|c|}
\hline $\begin{array}{l}\text { Glifosato } \\
\text { (Glicina substituída) } \\
(1071-83-6)\end{array}$ & Herbicida & $\begin{array}{l}\text { Algodão, ameixa, arroz, banana, cacau, } \\
\text { café, cana-de-açúcar, citros, coco, } \\
\text { feijão, fumo, maçã, mamão, milho, } \\
\text { nectarina, pastagem, pera, pêssego, } \\
\text { seringueira, soja, trigo e uva. Domissa- } \\
\text { nitário: jardinagem amadora. }\end{array}$ & Autorizado & Autorizado & Autorizado \\
\hline Pentaclorofenol (87-86-5) & - & - & Excluído & Autorizado & Não autorizado \\
\hline
\end{tabular}

Anvisa: Agência Nacional de Vigilância Sanitária.

US EPA: US Environmental Protection Agency.

EFSA: European Food Safety Authority .

Os efeitos carcinogênicos oriundos dos agrotóxicos ou de outros agentes podem ser causados por diferentes mecanismos, sendo os principais deles: alteração do reparo do DNA ou instabilidade genômica, caráter eletrofílico, genotoxicidade (e.g. dano cromossômico), alterações epigenéticas, estresse oxidativo, inflamação crônica, imunossupressão, modulação de efeitos mediados por receptores, imortalização celular, proliferação celular e morte celular (IARC, 2015A, 2015B). Esses mecanismos são avaliados pela Iarc durante o processo de classificação de um agente quanto ao seu potencial carcinogênico. Baseado em estudos epidemiológicos com exposição a agrotóxicos e ensaios in vitro e in vivo, os herbicidas (2,4-D e glifosato) e os inseticidas (diazinona e malationa) atuam através de cinco entre dez mecanismos de carcinogenicidade relevantes (quadro 4) (IARC, 2015A; IARC, 2015B). É possível observar que alguns ingredientes ativos atuam através dos mesmos mecanismos, o que destaca a preocupação sobre a interação entre eles e os possíveis impactos para a exposição humana. Essa questão é muito importante para a análise da problemática em questão, já que esses IAs são utilizados concomitantemente no meio rural ou urbano e, também, estão autorizados a ser adicionados conjuntamente à formulação de produtos comerciais. De maneira geral, os efeitos carcinogênicos que mais apresentam dados positivos nas monografias da Iarc são os efeitos genotóxicos, que podem resultar em danos cromossômicos, sendo esse o principal mecanismo descrito para o LNH. Outrossim, destacam-se os resultados de imunossupressão para 2,4-D e da diazinona em ensaios in vitro com células humanas, e para o 2,4-D em humanos, também associado ao LNH (GREER ET AL., 2009).

Um estudo canadense de seis províncias, com 513 casos de LNH e 1.506 controles, avaliou a exposição a misturas e obteve maiores medidas de associação ( $\mathrm{OR}$ = razão de chances) para o uso de malationa $+2,4-\mathrm{D}$ (OR = 2,06 IC95\% 1,45 - 2,93) do que desses IAs isolados (malationa: OR = 1,73, IC95\% 0,81-3,66; 2,4-D: OR = 0,94; IC95\% 0,67 - 1,33). O mesmo foi encontrado para malationa + glifosato (OR = 2,10; IC95\% 1,31-3,37; malationa: OR = 1,95; IC95\% 1,29-2,93; glifosato OR = 0,92; IC95\% 0,54-1,55) (HONENADEL ET AL., 2011). Um dos mecanismos de carcinogenicidade do linfoma não Hodgkin causado por exposição a agrotóxicos, e descrito nos estudos avaliados, consiste de um tipo de dano genotóxico chamado translocação cromossômica, que consiste no rearranjo de partes dos cromossomos 14 e 18, [t (14; 18)] (q32; q21). Essa aberração cromossômica ocorre em 70-90\% dos casos de linfoma folicular, 20-30\% de linfoma difuso de células B grandes e 5-10\% de outros subtipos menos comuns. Supõe-se que aberrações cromossômicas possam causar rearranjos nas imunoglobulinas das células $\mathrm{B}$ ou nos receptores das células $\mathrm{T}$, principalmente devido às translocações cromossômicas e, também, à superexpressão de oncogenes nas células linfoides imaturas da medula óssea ou em células maduras dos tecidos linfoides periféricos (CHIU; BLAIR, 2009). 
Quadro 4. Mecanismos de carcinogenicidade dos ingredientes ativos registrados no Brasil e com resultados de associação positiva com linfoma não Hodgkin (LNH)

\begin{tabular}{|c|c|c|c|c|}
\hline \multirow{3}{*}{ Mecanismos carcinogênicos ${ }^{1}$} & \multicolumn{4}{|c|}{ Tipos de estudos / ensaios } \\
\hline & \multirow{2}{*}{ Epidemiológicos } & \multicolumn{2}{|c|}{ In vitro } & \multirow{2}{*}{$\begin{array}{c}\text { In vivo } \\
\text { Mamíferos ou outras espécies }\end{array}$} \\
\hline & & Células humanas & Células não humanas & \\
\hline $\begin{array}{l}\text { Alterações na proliferação celular, morte } \\
\text { celular ou fornecimento de nutrientes }\end{array}$ & $2,4-D$ & $\begin{array}{l}\text { Diazinona } \\
\text { Malationa } \\
\text { Glifosato }\end{array}$ & Diazinona & $\begin{array}{l}\text { Diazinona } \\
\text { Malationa }\end{array}$ \\
\hline Efeitos genotóxicos & $\begin{array}{l}\text { 2,4-D } \\
\text { Diazinona } \\
\text { Glifosato } \\
\text { Malationa }\end{array}$ & $\begin{array}{l}\text { Diazinona } \\
\text { Glifosato } \\
\text { Malationa }\end{array}$ & $\begin{array}{l}\text { 2,4-D } \\
\text { Malationa } \\
\text { Glifosato }\end{array}$ & $\begin{array}{l}\text { 2,4-D } \\
\text { Diazinona } \\
\text { Malationa }\end{array}$ \\
\hline Estresse oxidativo & Malationa & $\begin{array}{l}\text { 2,4-D } \\
\text { Diazinona } \\
\text { Glifosato } \\
\text { Malationa }\end{array}$ & $\begin{array}{l}\text { Diazinona } \\
\text { Malationa }\end{array}$ & $\begin{array}{l}\text { 2,4-D } \\
\text { Diazinona } \\
\text { Glifosato } \\
\text { Malationa }\end{array}$ \\
\hline Imunossupressão & $2,4-D$ & $\begin{array}{l}2,4-\mathrm{D} \\
\text { Diazinona }\end{array}$ & Malationa & $\begin{array}{l}\text { 2,4-D } \\
\text { Diazinona } \\
\text { Glifosato } \\
\text { Malationa }\end{array}$ \\
\hline Inflamação crônica & - & - & Glifosato & $\begin{array}{l}\text { 2,4-D } \\
\text { Diazinona } \\
\text { Malationa }\end{array}$ \\
\hline $\begin{array}{l}\text { Modulação de efeitos mediados por receptor } \\
\text { (incluindo desregulação endócrina) }\end{array}$ & $2,4-D$ & 2,4-DGlifosato & Glifosato & $\begin{array}{l}\text { 2,4-D } \\
\text { Diazinona } \\
\text { Malationa }\end{array}$ \\
\hline
\end{tabular}

Fonte: Iarc (2015a, 2015b).

1 Os dados sobre os mecanismos de carcinogenicidade para cada ingrediente ativo foram obtidos a partir das respectivas monografias da larc, considerando-se o peso das evidências dos estudos apresentados.

As informações referentes aos mecanismos carcinogênicos do 2,4-D, glifosato, diazinona e malationa corroboram as associações positivas encontradas nos estudos epidemiológicos selecionados. Apesar disso, estudos publicados sobre a exposição ocupacional e ambiental a agrotóxicos e o risco de desenvolvimento de LNH apresentam resultados controversos, sendo que uma das principais limitações apontadas para a determinação do nexo causal é a dificuldade de identificação dos ingredientes ativos em amostras clínicas. Essa dificuldade pode se dar por conta de fatores como metodologias analíticas disponíveis na rede de laboratório, diversidade de metabólitos e aspectos toxicocinéticos, como meia-vida curta, que resulta na rápida eliminação do agente (ALAVANJA ET AL., 2014). Com isso, a curta janela de tempo entre a exposição e a possibilidade de coleta e análise da amostra pode inviabilizar a detecção do agente nas matrizes biológicas. Além disso, a maioria dos estudos encontrados na literatura pesquisada foi centrada na exposição de agricultores e aplicadores, e as principais limitações estão relacionadas ao viés de memória, devido ao fato de os trabalhadores nem sempre recordarem os IAs ou as misturas utilizadas, e de também não registrarem detalhes sobre a duração e a frequência de aplicação dos agrotóxicos. Esses aspectos são superestimados dentro do modelo reducionista adotado pelas agências reguladoras para selecionar os estudos utilizados para avaliar o risco de um IA de agrotóxico durante o processo de autorização de uso. É importante ressaltar que os estudos devem ser avaliados em conjunto, ou 
seja, mesmo que alguns dados epidemiológicos apresentem limitações que são inerentes a qualquer pesquisa com seres humanos, os achados de estudos experimentais, realizados com animais de laboratório ou sistemas in vitro, podem fortalecer as hipóteses de associação de um agente a um efeito tóxico, que, no momento do registro nos órgãos reguladores, dificilmente são observados. Isso porque os agrotóxicos têm sua comercialização autorizada considerando um cenário de exposição distinto da realidade, sem levar em conta o uso conjunto dos IAs e, consequentemente, os potenciais efeitos gerados, utilizados na agricultura, ou mesmo aqueles que já estão presentes nas formulações comerciais (FRIEDRICH, 2013). Por outro lado, do ponto de vista das ações de vigilância em saúde, esses estudos epidemiológicos realizados com populações expostas a misturas apontam a situação de extrema vulnerabilidade imposta pela realidade do uso adotada na agricultura brasileira e a insuficiência da estrutura regulatória e das legislações vigentes para evitar doenças crônicas, não somente o LNH, mas, também, outros tipos de câncer.

Os ingredientes ativos 2,4-D, glifosato e malationa estão registrados no Brasil para as culturas de arroz, café, milho, trigo, pastagens e soja. Além deles, o 2,4-D e o glifosato estão autorizados para as culturas de cana-de-açúcar e sorgo; e, para uso domissanitário, a diazinona, a malationa e o glifosato estão permitidos. Como esses agentes apresentam mecanismos de carcinogenicidade semelhantes e estão autorizados para os mesmos fins, a probabilidade de gerarem efeitos sinérgicos é grande, o que pode favorecer o desenvolvimento do câncer e, mais especificamente, do LNH. Portanto, as agências reguladoras deveriam adotar diretrizes que restringissem a comercialização de formulações com misturas de ingredientes ativos que tenham mecanismos de ação tóxica semelhantes para uma mesma cultura. Para isso, os órgãos responsáveis pela fiscalização e os profissionais que emitem os receituários agronômicos também devem estar informados que o uso concomitante de agrotóxicos pode aumentar o risco de doenças para o meio ambiente e para as pessoas que moram, estudam, trabalham ou circulam no entorno das lavouras.

Os dois IAs de agrotóxicos mais usados no Brasil (IBGE, 2015) são os herbicidas glifosato e 2,4-D, para os quais já vêm sendo identificadas plantas resistentes indesejáveis. Apesar disso, foi aprovada a liberação comercial de sementes transgênicas resistentes, ao mesmo tempo, a esses dois herbicidas $\left(\mathrm{CIB}_{\mathrm{B}}\right.$, 2015). O pacote tecnológico desenvolvido por uma empresa inclui, além da semente transgênica resistente ao glifosato e ao 2,4-D, a formulação de um produto que contém os dois herbicidas. Desse modo, estima-se que a utilização dessa tecnologia leve ao aumento do uso desses herbicidas, aumentando, assim, o risco dos impactos sobre a saúde e o ambiente, que podem ser potencializados com o uso concomitante desses dois Ias, associados à indução de LNH.

A lei brasileira preconiza que os agrotóxicos somente podem ser utilizados no País se forem registrados em órgão federal competente, de acordo com as diretrizes e exigências dos órgãos responsáveis pelos setores da saúde, do meio ambiente e da agricultura (CARNEIRO ET AL., 2015). O registro é realizado pelo Mapa, mas com a anuência do Ministério da Saúde (MS), através da Anvisa, e do Ministério do Meio Ambiente (MMA), por meio do Instituto Brasileiro do Meio Ambiente e dos Recursos Naturais Renováveis (Ibama).

Desde 2006, a Anvisa tem realizado a reavaliação toxicológica de diversos agrotóxicos, incluindo o 2,4-D (Resolução $\mathrm{n}^{\circ}$ $124 \mathrm{~A} / 2006$ ) e o glifosato (Resolução $\mathrm{n}^{\circ}$ 10/2008). Isso ocorre porque muitos tiveram seus registros realizados décadas atrás, quando as metodologias científicas eram pouco avançadas, principalmente no que se refere aos efeitos detectáveis no âmbito genômico ou de receptores e reguladores celulares (ANVISA, 2016). Todavia, a judicialização 
recorrente do processo de reavaliação toxicológica realizada pelos fabricantes e a sobreposição dos interesses do setor agrícola frente à proteção da vida humana prolongam o tempo de permanência desses produtos no mercado nacional.

\section{Conclusões}

No estudo em questão, foi possível evidenciar a existência de ingredientes ativos de agrotóxicos com associação positiva ao desenvolvimento de LNH e que também já haviam sido classificados recentemente pela Iarc quanto ao potencial carcinogênico: 2,4-D, diazinona, glifosato e malationa. O uso de agrotóxicos e o aumento das taxas de incidência do LNH são temas explorados pela área acadêmica, por agências internacionais voltadas para o controle e a prevenção do câncer e pelas políticas nacionais e internacionais voltadas para essa problemática. Este trabalho procurou abordar de maneira interdisciplinar o tema estudado com o intuito de subsidiar medidas intersetoriais para controle, prevenção e vigilância do câncer no Brasil, referentes ao uso de agrotóxicos.

A questão abordada neste ensaio mostra-se, portanto, de extrema relevância para as ações de vigilância, uma vez que as autoridades regulatórias autorizam o uso concomitante de agrotóxicos que apresentam mecanismos de carcinogenicidade semelhantes e que aumentam o risco de aparecimento de câncer.

Diante desse cenário de extrema vulnerabilidade da população brasileira a doenças causadas pelos agrotóxicos, diretrizes regulatórias e legislações mais restritivas são urgentes, assim como o investimento em serviços de saúde e a promoção de políticas de prevenção de doenças crônicas não transmissíveis.

\section{Referências}

AGÊNCIA NACIONAL DE VIGILÂNCIA SANITÁRIA (ANVISA). Regularização de Produtos - Agrotóxicos: reavaliação de agrotóxicos. Disponível em: $<$ http://portal.anvisa.gov.br/registros-e-autorizacoes/agrotoxicos/ produtos/reavaliacao-de-agrotoxicos>. Acesso em: 3 ago. 2016.

ALAVANJA, M. C. R. F. et al. Non-Hodgkin Lymphoma Risk and Insecticide, Fungicide and Fumigant Use in the Agricultural Health Study. PLOS ONE, San Francisco, v. 9, n. 10, out. 2014.

ASSOCIAÇÃO BRASILEIRA DE SAÚDE COLETIVA
(ABRASCO). Nota técnica sobre microcefalia e doenças vetoriais relacionadas ao Aedes aegypti: os perigos das abordagens com larvicidas e nebulizações químicas: fumacê. Disponível em: <https://www.abrasco.org. $\mathrm{br} /$ site/2016/02/nota-tecnica-sobre-microcefalia-e-doencas-vetoriais-relacionadas-ao-aedes-aegypti-os-perigos-das-abordagens-com-larvicidas-e-nebulizacoes-quimicas-fumace/>. Acesso em: 28 ago. 2016.

BOCCOLINI, P. M.; BOCCOLINI, C. S.; MEYER, A. Tendência de mortalidade por linfomas não Hodgkin no Brasil, 1980 a 2012. Cad. Saúde Colet. Rio de Janeiro, v. 23, n. 2, p. 188-197, 2015. 
BRÃUNER, E. V.; SORENSEN, M.; GAUDREAU, E. et al. A Prospective Study of Organo chlorines in Adipose Tissue and Risk of Non-Hodgkin Lymphoma. Environmental Health Perspectives, Nova York, v. 120, n. 1, jan. 2012.

BURNS, C. et al. Cancer Incidence of 2,4-D Production Workers. Int. J. Environ. Res. Public Health, Basel, v. 8, p. 3579-3590, 2011.

CARNEIRO, F. F. (Org.). Dossiê ABRASCO: um alerta sobre os impactos dos agrotóxicos na saúde. Rio de Janeiro: Escola Politécnica de Saúde Joaquim Venâncio, 2015.

CHIU, B. C. H.; BLAIR, A. Pesticides, Chromosomal Aberrations, and Non-Hodgkin's Lymphoma. $J$ Agromedicine, Binghamton, v. 14, n. 2, p. 250-255. 2009

\section{CONSELHO DE INFORMAÇÕES SOBRE}

BIOTECNOLOGIA (CIB). DAS-40278-9 x NK603. 2015

Disponível em: $<$ http://cib.org.br/produtos-aprovados/ das-40278-9-x-nk603/>. Acesso em: 14 mar. 2017.

FRIEDRICH, K. Desafios para a avaliação toxicológica de agrotóxicos no Brasil: desregulação endócrina e imunotoxicidade. Vigilância Sanitária em Debate, Rio de Janeiro, v.1, n. 2, p. 2-15, 2013.

GOODMAN, J. E.; LOFTUS, C. T.; ZU, K. 2,4

Dichlorophenoxyacetic acid and non-Hodgkin's lymphoma, gastric cancer, and prostate cancer: meta-analyses of the published literature. Annals of Epidemiology, Nova York, v. 25, n. 8, p. 626-636, 2015.

GREER, J. P.; REDDY, N. M.; WILLIANS, M. E. NonHodgkin Lymphoma in Adults. In: GREER, J. P. et al. (Org.). Wintrobe's clinical hematology, 2009. p. 1827-1837.

HOHENADEL, K. et al. Exposure to Multiple Pesticides and Risk of Non-Hodgkin Lymphoma in Men from Six Canadian Provinces. Int. J. Environ. Res. Public Health, Basel, v. 8, p. 2320-2330, 2011.

INSTITUTO NACIONAL DO CÂNCER (INCA).
Estimativa 2016: incidência de câncer no Brasil. Rio de Janeiro: INCA, 2015.

\section{INTERNATIONAL AGENCY FOR RESEARCH ON}

CANCER (IARC). Monographs Volume 112: evaluation of five organophosphate insecticides and herbicides. 2015a. Disponível em: <https://www.iarc.fr/en/mediacentre/iarcnews/pdf/MonographVolumell2.pdf>. Acesso em: 1 ago. 2016.

\section{INTERNATIONAL AGENCY FOR RESEARCH ON}

CANCER (IARC). 2,4-Dichlorophenoxyacetic Acid. 2015b. Disponível em: <http://monographs.iarc.fr/ ENG/Monographs/vol113/monoll3-03.pdf>. Acesso em: 1 ago. 2016.

LERRO, C. C. et al. Organophosphate insecticide use and cancer incidence among spouses of pesticide applicators in the Agricultural Health Study. Occup Environ Med, Londres, n. 72, p. 736-744, 2015.

LUO, D. et al. Exposure to organochlorine pesticides and non-Hodgkin lymphoma: a meta-analysis of observational studies. Scientific Reports, Londres, n. 6, p. 257-68, 2016.

PAHWA, M. et al. Pesticide use, immunologic conditions, and risk of non-Hodgkin lymphoma in Canadian men in six provinces. Int. J. Cancer, Genebra, v. 131, n. 11, p. 2650-2659, 2012.

PARRÓN, T. et al. Environmental exposure to pesticides and cancer risk in multiple human organ systems. Toxicology Letters, Amsterdam, v. 230, n. 2, p. 157-165, 2014.

RUDER, A. M.; YIIN, J. H. Mortality of US pentachlorophenol production workers throught 2005. Chemosphere, Oxford, v. 83, n. 6, p. 851-861, 2011.

SCHINASI, L. H.; LEON, M. E. Non-Hodgkin

Lymphoma and Occupational Exposure to Agricultural Pesticide Chemical Groups and Active Ingredients: A Systematic Review and Meta-Analysis. Int. J. Environ. Res. Public Health, Basel, v. 11, n. 4, p. 4449-4527, 2014. 
SCHINASI, L. H. et al. Insecticide exposure and farm history in relation to risk of lymphomas and leucemias in the Women's Health Iniative observational study cohort. Annals of Epidemiology, Nova York, v. 25, n. 11, p. $803-810,2015$.

VIEL, J.; DE ROOS, A. J.; RAY, R. M. Increased risk of non-Hodgkin lymphoma and serum organochlorine. Environmental International, Oxford, v. 37, n. 2, p. 449453, 2011.

WHITTEMORE, R.; KNAFL, K. The integrative review: updated methodology. J Adv Nurs, Oxford, v. 52, n. 5, p. 546-553, 2005.
ZAKERINIA M.; NAMDARI, M.; AMIRGHOFRAN, S. The Relationship between Exposure to Pesticides and the Occurrence of Lymphoid Neoplasm. Iran Red Crescent Med J, Dubai, v. 14, n. 6, p. 337-344, 2014.

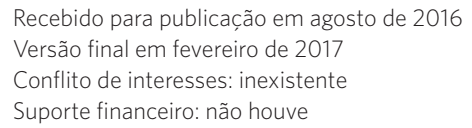

